\title{
Effect of water addition to a total mixed ration on feed temperature, feed intake, sorting behavior, and milk production of dairy cows
}

\author{
C. A. Felton and T. J. DeVries ${ }^{1}$ \\ Department of Animal and Poultry Science, University of Guelph, Kemptville Campus, Kemptville, Ontario, K0G 1J0, Canada
}

\begin{abstract}
The objective of this study was to determine the effects of water addition to a high-moisture total mixed ration (TMR) on feed temperature, feed intake, feed sorting behavior, and milk production of dairy cows. Twelve lactating Holstein cows (155.8 \pm 60.1 DIM), individually fed once daily at $1000 \mathrm{~h}$, were exposed to 3 diets in a Latin square design with 28-d treatment periods. Diets had the same ingredient composition [30.9\% corn silage, $30.3 \%$ alfalfa haylage, $21.2 \%$ highmoisture corn, and $17.6 \%$ protein supplement; dry matter (DM) basis] and differed only in DM concentration, which was reduced by the addition of water. Treatment diets averaged 56.3, 50.8, and 44.1\% DM. The study was conducted between May and August when environmental temperature was $18.2 \pm 3.6^{\circ} \mathrm{C}$ and ambient temperature in the barn was $24.4 \pm 3.3^{\circ} \mathrm{C}$. Dry matter intake (DMI) was monitored for each animal for the last $14 \mathrm{~d}$ of each treatment period. For the final $7 \mathrm{~d}$ of each period, milk production was monitored, feed temperature and ambient temperature and humidity were recorded (daily at 1000, 1300, and $1600 \mathrm{~h}$ ), and fresh feed and orts were sampled for determination of sorting. For the final $4 \mathrm{~d}$ of each period, milk samples were taken for composition analysis. Samples taken for determining sorting were separated using a Penn State Particle Separator that had 3 screens $(19,8$, and 1.18 $\mathrm{mm}$ ) and a bottom pan, resulting in 4 fractions (long, medium, short, and fine). Sorting was calculated as the actual intake of each particle size fraction expressed as a percentage of the predicted intake of that fraction. Greater amounts of water added to the TMR resulted in greater increases in feed temperature in the hours after feed delivery, greater sorting against long particles, and decreased DMI, reducing the overall intake of starch and neutral detergent fiber. Milk production and composition were not affected by the addition of water to the TMR. Efficiency of production of milk was, however, increased with greater amounts of water
\end{abstract}

Received December 17, 2009.

Accepted March 4, 2010.

${ }^{1}$ Corresponding author: tdevries@kemptvillec.uoguelph.ca added to the TMR. The increases in feed temperature in the hours after feed delivery were enhanced by higher ambient temperatures; this may be indicative of feed spoilage and thus may have contributed to the reduced DMI observed. Overall, these results suggest that the addition of water to high-moisture TMR (less than $60 \%$ DM) containing primarily haylage and silage forage sources will not always discourage cows from sorting, but rather may increase this behavior and limit the nutrient consumption of cows, particularly when ambient temperature is high.

Key words: feed temperature, dry matter concentration, sorting behavior, dairy cow

\section{INTRODUCTION}

The sorting of TMR by dairy cows can result in the ration actually consumed by cows being higher in fermentable carbohydrates than intended and lower in effective fiber, thereby increasing the risk of SARA (DeVries et al., 2008). The addition of water to dry TMR has traditionally been considered a beneficial management practice to reduce the amount of feed sorting (Shaver, 2002). Leonardi et al. (2005) demonstrated that reducing TMR DM concentration from 80 to $64 \%$ through water addition resulted in a reduction in the extent of feed sorting against long particles and in favor of short particles, a tendency for increased NDF intake, and higher milk fat percentage (3.41 vs. 3.31\%). Interestingly, the ration tested in that study was much drier than that typically used for high-production dairy herds (40-60\% DM; Eastridge, 2006), particularly those using no dry forages in their TMR.

Miller-Cushon and DeVries (2009) recently found that, for a TMR containing primarily haylage and silage forage sources, reducing the DM concentration from 57.6 to $47.9 \%$ through water addition actually encouraged greater feed sorting and reduced DMI. Similarly, a linear reduction in DMI with decreasing dietary DM concentration $(78,65,53$, and $40 \% \mathrm{DM})$ had previously been documented (Lahr et al., 1983). Reduced DMI with lower dietary DM is likely attributable, in part, to the increased filling effect of higher moisture rations (Robinson et al., 1990; Miller-Cushon 
and DeVries, 2009). It has been previously suggested that higher moisture TMR are less stable (i.e., more prone to spoilage) during periods of increased environmental temperature (Eastridge, 2006). The study by Miller-Cushon and DeVries (2009) was conducted during the summer months, and therefore it could also be hypothesized that the reduced intake and greater sorting was the result of spoilage in the feed bunk. It is possible to identify such spoilage through changes in feed characteristics such as temperature, $\mathrm{pH}$, and yeast counts (Kung et al., 1998). Unfortunately, there were no measures of change in feed characteristics in the feed bunk over the day in that previous study.

The objective of this experiment was to examine the effect of water addition to TMR on feed temperature, feed intake, feed sorting behavior, and milk production. The hypothesis of this experiment was that adding water to TMR would increase feed temperature, particularly in situations of high ambient temperatures, and result in increased feed sorting, decreased feed nutrient intake, and decreased milk production.

\section{MATERIALS AND METHODS}

\section{Animals and Housing}

Twelve lactating Holstein dairy cows, 1 primiparous and 11 multiparous (parity $=3.7 \pm 2.0$; mean $\pm \mathrm{SD}$ ), were used in this experiment. Animals were $155.8 \pm$ 60.1 DIM at the beginning of the data collection period. Cows were housed together in a tie-stall barn located at the University of Guelph, Kemptville Campus Dairy Education and Research Centre (Kemptville, Ontario, Canada) and were managed according to the guidelines set by the Canadian Council on Animal Care (1993). Each cow was individually housed in a tie-stall with ad libitum access to water (via an individual water bowl) and feed (via a feed bunk containing dividers separating adjacent cows' feed). Each cow was fed a TMR (Table 1) once daily at $1000 \mathrm{~h}$. Orts from each feeding were removed from the feed bunk before the subsequent feed delivery. Cows were milked in their stalls twice daily at 0500 and $1600 \mathrm{~h}$. Cows were given a 2-h exercise period (0800-1000 h) each day in an outdoor dry lot pen. The experiment was conducted between May 28 and August 20 . The average environmental temperature during the experiment was $18.2 \pm 3.6^{\circ} \mathrm{C}$.

\section{Experimental Design and Diets}

The number of animals required per treatment was determined through power analysis (Morris, 1999) for the primary response variables, including DMI, feed sorting, and milk production and composition. Estimates of
Table 1. Ingredient and chemical composition of the basal diet

\begin{tabular}{lc}
\hline Composition & Value \\
\hline Ingredient, \% DM $^{\text {Corn silage }}{ }^{1}$ & \\
Alfalfa haylage $^{2}$ & 30.9 \\
High moisture corn $^{3}$ & 30.3 \\
Concentrate pellet $^{3}$ & 21.2 \\
Chemical composition, ${ }^{4}$ \% of DM unless noted & 17.6 \\
OM & \\
CP & $92.1 \pm 0.4$ \\
ADF & $17.0 \pm 0.6$ \\
NDF & $22.8 \pm 1.8$ \\
NFC & $32.9 \pm 2.3$ \\
Starch & $40.2 \pm 2.1$ \\
NE $_{\mathrm{L}}$, Mcal/kg of DM & $27.7 \pm 1.6$ \\
\hline
\end{tabular}

${ }^{1}$ Corn silage had a DM of $43.6 \pm 3.4 \%$ and chemical composition (DM basis) of $7.9 \pm 0.2 \% \mathrm{CP}, 20.9 \pm 0.9 \% \mathrm{ADF}$, and $35.2 \pm 1.0 \% \mathrm{NDF}$. Particle size distribution of corn silage (DM basis) was $5.4 \pm 1.7 \%$ long, $58.8 \pm 6.5 \%$ medium, $31.7 \pm 4.6 \%$ short, and $4.1 \pm 2.4 \%$ fine particles.

${ }^{2}$ Alfalfa haylage had a DM of $50.5 \pm 2.9 \%$ and chemical composition (DM basis) of $17.0 \pm 1.7 \% \mathrm{CP}, 42.9 \pm 4.3 \% \mathrm{ADF}$, and $52.9 \pm 4.3 \%$ NDF. Particle size distribution of alfalfa haylage (DM basis) was 15.5 $\pm 9.4 \%$ long, $45.5 \pm 6.3 \%$ medium, $31.9 \pm 5.6 \%$ short, and $7.1 \pm 2.1 \%$ fine particles.

${ }^{3}$ Supplied by Ritchie Feed \& Seed Inc. (Ottawa, Ontario, Canada), containing (on as-is basis): $30.3 \%$ soybean meal, $24.2 \%$ Tri-Pro Gold (Tri-County Protein Corp., Winchester, Ontario, Canada), 16.5\% corn gluten meal, $11.0 \%$ canola meal, $5.9 \%$ ground limestone, $5.8 \%$ trace mineral-vitamin premix, $4.1 \%$ sodium bicarbonate, and $2.2 \%$ cobaltized-iodized salt.

${ }^{4}$ Values were obtained from chemical analysis of TMR samples. OM = $100-\%$ ash. $\mathrm{NFC}=100-(\% \mathrm{CP}+\% \mathrm{NDF}+\%$ fat $+\%$ ash $) . \mathrm{NE}_{\mathrm{L}}$ was calculated based on NRC (2001) equations.

variation for these variables were based on previously reported values (Leonardi et al., 2005; DeVries et al., 2007; Bhandari et al., 2008; Miller-Cushon and DeVries, 2009). Cows were exposed to each of 3 treatments in a quadruplicated $3 \times 3$ Latin square design. The 4 squares were conducted simultaneously and comprised cows similar in DIM. Cows within a square were assigned to dietary treatments such that, across squares, cows on each treatment were balanced for DIM, milk production, and average parity.

Cows were exposed, in 28-d periods, to each of 3 treatments: control diet (hereafter, the dry treatment; target $60 \% \mathrm{DM}$ ), control diet with added water (hereafter, the wet treatment; target $54 \% \mathrm{DM}$ ), and control diet with added water (hereafter, the wetter treatment; target $48 \% \mathrm{DM})$. The control diet was formulated to meet the nutrient requirements of lactating dairy cows producing $40 \mathrm{~kg} / \mathrm{d}$ (NRC, 2001). Dietary components were mixed for approximately $10 \mathrm{~min}$ in a TMR mixer wagon (Reel-Auggie model 3250, Kuhn Knight Inc., Brodhead, WI). After mixing, the ration for the cows on the dry treatment was transferred to an automatic feeder (Mullerup Smartfeeder M2000, Crysler, Ontario, Canada) from which these cows were fed. For the wet 
and wetter treatments the mixed ration was transferred in separate batches to a feed cart (WIC MDR-55, Ideal Machinery Inc., Wickham, Quebec, Canada), where the appropriate amount of water was added, and then the ration was fed to the cows. To decrease the dietary DM concentration from approximately 60 to $54 \%$ for the wet treatment and from 54 to $48 \%$ for the wetter treatment, the amount of water added constituted 20 and $44 \%$ of the diet (DM basis), respectively. Load cells of the automatic feeder and feed cart were calibrated at the beginning of the experiment to ensure accuracy in delivered feed amounts. Prior to feed delivery, mixing times of the treatment rations within the automatic feeder and feed cart were similar. The amount of feed offered to each cow was adjusted daily to ensure approximately $15 \%$ orts.

\section{Ambient and Feed Temperatures}

Ambient temperature and relative humidity in the barn were recorded 3 times daily (at 1000, 1300, and $1600 \mathrm{~h}$ ) on the last $7 \mathrm{~d}$ of each treatment period using a digital thermometer (VWR 4040 clock/humidity monitor, Control Company, Friendswood, TX) located in the middle of the facility. Temperature-humidity index (THI) was calculated following Ravagnolo et al. $(2000): \mathrm{THI}=(1.8 t+32)-[(0.55-0.0055 \mathrm{RH}) \times(1.8 t$ $-26)]$; with $t=$ air temperature $\left({ }^{\circ} \mathrm{C}\right)$ and $\mathrm{RH}=$ relative humidity $(\%)$. Feed temperature was recorded using a hand-held forage moisture/temperature probe (New Holland HMT-2, Farmex Electronics Corp., Streetsboro, $\mathrm{OH})$. This probe was inserted into the center of the feed pile in each cow's feed bunk at 1000, 1300, and $1600 \mathrm{~h}$ on the last $7 \mathrm{~d}$ of each treatment period and the displayed temperature was recorded. On one day in each treatment period, feed temperature for each cow was also recorded at 1000, 1300, and $1600 \mathrm{~h}$ using a hand-held digital thermal imaging camera (Fluke Ti40, Fluke Corporation, Everett, WA). Images were taken approximately $1.2 \mathrm{~m}$ from the top surface of each feed pile. From the images taken, mean surface temperature of the feed was computed.

\section{Feed Sampling and Analysis}

Representative samples of the treatment TMR and individual orts of each cow were taken daily during the last $14 \mathrm{~d}$ of each treatment period for determination of DM and nutrient concentration. During the last 7 $\mathrm{d}$ of each period duplicate samples of the TMR and individual orts of each cow were taken for particle size separation. Additionally, on d 7, 14, 21, and 28 of each treatment period, duplicate samples of the dietary components were taken for particle size and chemical analysis. All samples were immediately frozen at $-20^{\circ} \mathrm{C}$ until they were further analyzed.

Samples for particle size separation were separated using a 3-screen (19-, 8-, and 1.18-mm) Penn State Particle Separator (PSPS; Kononoff et al., 2003). This device separated the particles into 4 fractions: long $(>19$ $\mathrm{mm})$, medium $(<19$ and $>8 \mathrm{~mm})$, short $(<8$ and $>1.18$ $\mathrm{mm})$, and fine $(<1.18 \mathrm{~mm})$ particles. After separation, the DM of each separated fraction was determined by oven drying at $55^{\circ} \mathrm{C}$ for $48 \mathrm{~h}$. The physical effectiveness factor (pef) was determined as the DM proportion of particles retained by the top 2 sieves of the PSPS (Yang and Beauchemin, 2006). The physically effective NDF (peNDF) was calculated by multiplying the NDF content of the feed by the pef.

Samples taken for DM and chemical analysis were oven dried at $55^{\circ} \mathrm{C}$ for $48 \mathrm{~h}$ and then ground to pass through a 1-mm screen (Brinkmann Mill, Brinkmann Instruments Co., Westbury, NY). These samples, plus the dried TMR particle fractions, were sent to Cumberland Valley Analytical Services Inc. (Maugansville, MD) for analysis of DM $\left(135^{\circ} \mathrm{C}\right.$; AOAC, 2000: method 930.15), ash (535 C; AOAC, 2000: method 942.05), ADF (AOAC, 2000: method 973.18), NDF with heat-stable $\alpha$-amylase and sodium sulfite (Van Soest et al., 1991), and $\mathrm{CP}(\mathrm{N} \times$ 6.25) (AOAC 2000: method 990.03; Leco FP-528 nitrogen analyzer, Leco, St. Joseph, MI).

\section{Milk Production and Components}

Daily milk production (a.m. and p.m.) was recorded using Tru-test milk meters (Surge, Mississauga, Ontario, Canada) for the last $7 \mathrm{~d}$ of each treatment period. Milk samples were taken from each animal at each milking for the last $4 \mathrm{~d}$ of each treatment period. These samples were sent to the DHI testing laboratory (Ontario Dairy Herd Improvement Corp., Guelph, Ontario, Canada) for analysis. Milk samples were analyzed for milk protein and fat percentage using a near-infrared analyzer (Foss System 4000, Foss Electric, Hillerød, Denmark). Milk fat and protein yield $(\mathrm{kg} / \mathrm{d})$ were calculated for the last $4 \mathrm{~d}$ of each treatment period based on the product of the milk production yield and milk composition at each milking on those days. For those days, the yield of $4 \%$ FCM $(\mathrm{kg} / \mathrm{d})$ was calculated $(\mathrm{NRC}, 2001)$ as $0.4 \times$ milk yield $(\mathrm{kg} / \mathrm{d})+15.0 \times$ fat yield $(\mathrm{kg} / \mathrm{d})$. Efficiency of milk production was determined by calculating the kilograms of milk or 4\% FCM yield per kilogram of DMI for the last $4 \mathrm{~d}$ of each treatment period.

\section{Calculations and Statistical Analysis}

Sorting activity for each fraction of the PSPS was calculated as the actual intake of each fraction expressed 
as a percentage of the predicted intake of that fraction (Leonardi and Armentano, 2003). The predicted intake of an individual fraction was calculated as the product of the DMI of the total diet multiplied by the DM percentage of that fraction in the fed TMR. Values equal to $100 \%$ indicate no sorting, $<100 \%$ indicate selective refusals (sorting against), and $>100 \%$ indicate preferential consumption (sorting for).

A preliminary analysis of the effect of day within treatment period was conducted on the data to determine whether there was any change in response to treatments over the data collection periods. This analysis revealed no day effect and, therefore, data for the particle size distribution, pef and peNDF of the diets, and DM concentration of the TMR and orts, as well as the daily intakes, sorting activity, milk yield, milk composition, and efficiency of milk production were averaged for each cow by treatment period. To test whether sorting of the experimental diets occurred, sorting activity for each fraction of the PSPS was summarized by treatment and tested for a difference from 100 using $t$-tests. All data were then analyzed using the MIXED procedure of SAS (SAS Institute, 2003). The final model included the fixed effects of period, square, and treatment, the random effect of cow within square, and the residual error. Interactions of the period and square with treatment were tested in the model and were not significant; therefore, these are not further reported. Linear and quadratic orthogonal contrasts of treatment were tested using the CONTRAST statement of SAS. Data for feed temperature were summarized by sampling time $(1000,1300$, and $1600 \mathrm{~h}$ ) for each animal on each treatment. These data were analyzed using the MIXED procedure of SAS, treating time as a repeated measure. The model included the fixed effects of time, treatment, period and square, and the residual error. Cow within square was included in the model as the subject of the repeated statement. Interactions of time, period, and square with treatment were tested in the model and were not significant $(P$ $<0.2)$; therefore, these are not further reported. For this model, compound symmetry was selected as the covariance structure (to model covariance among repeated measures of feed temperature taken over time) on the basis of best fit according to Schwarz's Bayesian information criterion. All reported values are least squares means. Significance was declared at $P \leq 0.05$, and trends reported if $0.05<P \leq 0.10$.

To determine the effect of environmental conditions on feed temperature, the regression procedure of SAS was used to determine the linear relationship across treatments between measures of environmental condition (ambient temperature, relative humidity, and THI) and temperature of the feed recorded by the forage

Table 2. Dry matter concentration of treatment diets, particle size distribution, ${ }^{1}$ NDF and starch concentrations of the particle fractions, and effective fiber concentration of the treatment diets

\begin{tabular}{|c|c|c|c|c|c|c|}
\hline \multirow[b]{2}{*}{ Item } & \multicolumn{3}{|c|}{ Treatment $^{2}$} & \multirow[b]{2}{*}{ SE } & \multicolumn{2}{|c|}{ Effect } \\
\hline & Dry & Wet & Wetter & & Linear & Quadratic \\
\hline DM, $\%$ of TMR & 56.3 & 50.8 & 44.1 & 0.3 & $<0.001$ & 0.13 \\
\hline \multicolumn{7}{|l|}{ DM retained on screen, $\%$} \\
\hline Long & 3.4 & 2.9 & 3.5 & 0.3 & 0.75 & 0.19 \\
\hline Medium & 49.6 & 50.9 & 54.9 & 1.2 & 0.03 & 0.37 \\
\hline Short & 38.4 & 39.1 & 38.0 & 1.2 & 0.83 & 0.55 \\
\hline Fine & 8.6 & 7.1 & 3.6 & 0.5 & 0.003 & 0.20 \\
\hline \multicolumn{7}{|l|}{ NDF, $\%$ of screen DM } \\
\hline Long & 58.1 & 57.0 & 54.1 & 2.9 & 0.37 & 0.80 \\
\hline Medium & 37.1 & 36.2 & 36.1 & 0.8 & 0.43 & 0.68 \\
\hline Short & 29.6 & 29.0 & 28.0 & 0.3 & 0.02 & 0.59 \\
\hline Fine & 19.4 & 19.7 & 16.9 & 0.6 & 0.05 & 0.12 \\
\hline \multicolumn{7}{|l|}{ Starch, \% of screen DM } \\
\hline Long & 9.5 & 10.7 & 13.0 & 1.7 & 0.22 & 0.79 \\
\hline Medium & 29.0 & 31.7 & 31.2 & 0.8 & 0.11 & 0.17 \\
\hline Short & 28.2 & 30.2 & 28.6 & 0.8 & 0.70 & 0.14 \\
\hline Fine & 36.0 & 34.4 & 29.0 & 3.5 & 0.23 & 0.68 \\
\hline pef $^{3}$ & 53.1 & 53.8 & 58.4 & 1.3 & 0.05 & 0.30 \\
\hline peNDF, ${ }^{4} \%$ of DM & 18.1 & 18.3 & 19.9 & 0.5 & 0.06 & 0.29 \\
\hline
\end{tabular}

${ }^{1}$ Particle size determined by Penn State Particle Separator, which has a 19-mm screen (long), 8-mm screen (medium), 1.18-mm screen (short), and a pan (fine).

${ }^{2}$ Treatment: dry $=$ basal dry diet without water added; wet $=$ basal dry diet plus $20 \%$ water added (DM basis); wetter $=$ basal dry diet plus $44 \%$ water added (DM basis).

${ }^{3}$ pef $=$ physical effectiveness factor determined as the proportion of particles retained by top 2 sieves of the Penn State Particle Separator (Yang and Beauchemin, 2006).

${ }^{4}$ peNDF $=$ measured as the NDF content of the TMR (DM basis) multiplied by the pef. 
Table 3. Dry matter percentage of particle fractions ${ }^{1}$ for fresh feed and orts from the treatment diets

\begin{tabular}{|c|c|c|c|c|c|c|}
\hline \multirow[b]{2}{*}{ Item } & \multicolumn{3}{|c|}{ Treatment $^{2}$} & \multirow[b]{2}{*}{$\mathrm{SE}$} & \multicolumn{2}{|c|}{ Effect } \\
\hline & Dry & Wet & Wetter & & Linear & Quadratic \\
\hline \multicolumn{7}{|c|}{ DM, $\%$ of TMR particle fractions } \\
\hline Long & 50.1 & 45.0 & 38.5 & 0.9 & $<0.001$ & 0.55 \\
\hline Medium & 55.9 & 50.8 & 43.1 & 0.1 & $<0.001$ & $<0.001$ \\
\hline Short & 56.6 & 51.7 & 45.7 & 0.2 & $<0.001$ & 0.11 \\
\hline Fine & 58.8 & 55.9 & 49.9 & 0.4 & $<0.001$ & 0.05 \\
\hline \multicolumn{7}{|c|}{ DM, \% of orts particle fractions } \\
\hline Long & 43.9 & 39.4 & 36.8 & 1.9 & 0.01 & 0.58 \\
\hline Medium & 46.1 & 40.8 & 38.2 & 2.2 & 0.01 & 0.50 \\
\hline Short & 47.9 & 43.7 & 39.4 & 1.8 & 0.005 & 0.97 \\
\hline Fine & 56.0 & 54.2 & 52.9 & 0.4 & 0.005 & 0.70 \\
\hline
\end{tabular}

${ }^{1}$ Particle size determined by Penn State Particle Separator, which has a 19-mm screen (long), 8-mm screen (medium), 1.18-mm screen (short), and a pan (fine).

${ }^{2}$ Treatment: dry = basal dry diet without water added; wet = basal dry diet plus $20 \%$ water added (DM basis); wetter $=$ basal dry diet plus $44 \%$ water added (DM basis).

probe. In effort to determine how well thermal images of feed surface predict feed temperature, the regression procedure of SAS was used to determine the linear relationship across treatments between temperatures of the feed recorded using the infrared camera and the forage probe.

\section{RESULTS}

Nutrient composition and particle size distribution of treatment diets are reported in Tables 1 and 2 , respectively. The addition of water to the dry diet (range: $53-61 \% \mathrm{DM}$ ) reduced the DM by, on average, 6 and $12 \%$ to produce the wet (range: $48-57 \% \mathrm{DM}$ ) and wetter (range: $39-51 \%$ DM) diets, respectively (Table 2 ). The particle size distribution of the TMR was affected by the addition of water, with a linear increase in the amount of DM in the medium particle fraction and decrease in the fine particle fraction. As a result, there was a linear increase in pef with the addition of water and a tendency for a linear increase in peNDF. The NDF concentration of the short and fine particle fractions were linearly decreased with the addition of water to the diet. Starch concentration of the different particle fractions was not affected by the addition of water to the diet. The NDF concentration decreased with particle size for all treatments, whereas starch concentration was lesser for long particles and greater for the 3 smaller particle fractions. The DM percentage of the different particle fractions of the offered and refused TMR can be seen in Table 3. Dry matter percentage linearly decreased with water addition, whereas DM percentage increased with decreased particle size across treatments.

In the barn, the average ambient temperature was $24.4 \pm 3.3^{\circ} \mathrm{C}$ (mean $\pm \mathrm{SD}$; range: $14.9-31.9^{\circ} \mathrm{C}$ ), the av- erage humidity was $63.3 \pm 13.5 \%$ (range: $33.0-95.0 \%$ ), and average THI was $72.0 \pm 4.1$ (range: 58.5-88.6). The addition of water to the dry diet caused a linear reduction $(\mathrm{SE}=0.1 ; P<0.001)$ in feed temperature (Table 4). On average, the temperature of the treatment diets increased by $1.4^{\circ} \mathrm{C}(\mathrm{SE}=0.06 ; P<0.001)$ from 1000 to 1600 h. Feed temperature change over this period increased more with greater water added to the diet $(P=0.02)$. Overall, these feed temperatures were positively correlated to THI $(P<0.001$; Figure $1)$ and ambient temperature $\left(\mathrm{y}=0.85 \mathrm{x}-0.29 ; \mathrm{R}^{2}\right.$ $=0.76 ; P<0.001)$ and were negatively correlated to relative humidity $\left(\mathrm{y}=-0.17 \mathrm{x}+31.2 ; \mathrm{R}^{2}=0.26 ; P\right.$ $<0.001)$. Further, feed surface temperature recorded using a thermal image camera was positively correlated $(P<0.001 ;$ Figure 2$)$ with feed temperature recorded using a forage temperature probe.

Cows sorted against long particles $(>19.0 \mathrm{~mm})$ on all treatment diets; the degree of this sorting increased linearly with greater water addition to the diet (Table $5)$. There was no sorting in favor of or against medium particles $(<19.0$ and $>8.0 \mathrm{~mm})$ on any of the treatment diets. Cows sorted in favor of short particles $(<8.0$ and $>1.18 \mathrm{~mm}$ ) when fed the dry and wetter diets and tended to sort in favor of these particles on the wet

Table 4. Feed temperature $\left({ }^{\circ} \mathrm{C}\right)$ of treatment $\operatorname{diets}^{1}$ taken at 1000 , 1300 , and $1600 \mathrm{~h}$

\begin{tabular}{lllc}
\hline Time $(\mathrm{h})$ & Dry & Wet & Wetter \\
\hline 1000 & 20.2 & 19.6 & 19.3 \\
1300 & 20.9 & 20.6 & 20.3 \\
1600 & 21.3 & 21.1 & 20.9 \\
\hline
\end{tabular}

${ }^{1}$ Treatment: dry $=$ basal dry diet without water added; wet $=$ basal dry diet plus $20 \%$ water added (DM basis); wetter = basal dry diet plus $44 \%$ water added (DM basis). 

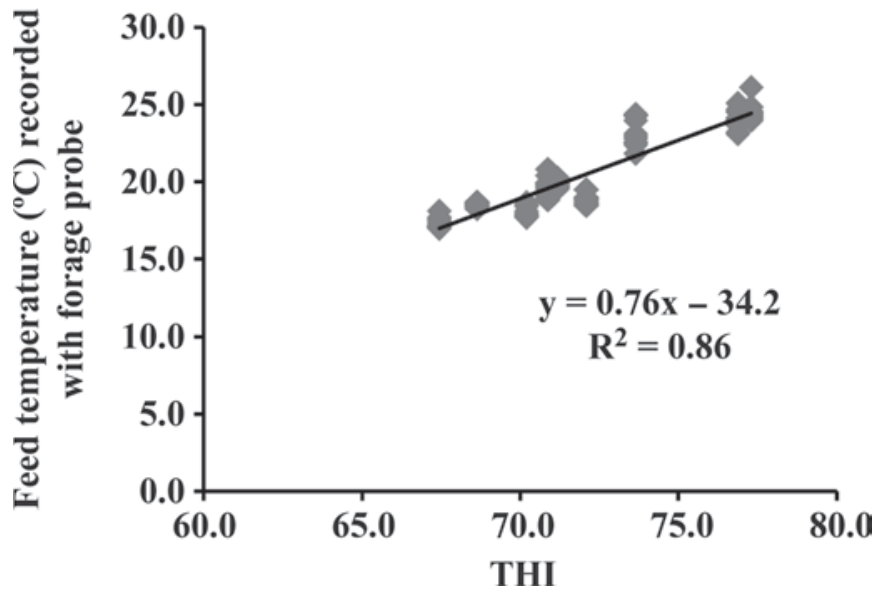

Figure 1. Linear regression model describing the relationship between feed temperature recorded using a forage temperature probe and temperature-humidity index (THI). Data were collected at 1000, 1300, $1600 \mathrm{~h}$ and are averaged over $7 \mathrm{~d}$ for 12 cows on each of 3 treatment diets (varying in DM concentration: $56.3,50.8$, and $44.1 \%$ ).

diet; there was no difference in the extent of this sorting between treatments. There was no sorting in favor of or against fine particles $(<1.18 \mathrm{~mm})$ on any of the treatment diets.

The difference in intakes between diets is reported in Table 6. There was a linear decrease in DMI with lower dietary DM concentration. However, there was a linear increase in the consumption of wet matter feed with lower dietary DM concentration, which corresponded to a quadratic increase in intake of water in the feed. Neutral detergent fiber and starch intake linearly decreased with the addition of water to the diet, whereas the NDF and starch concentration of diet consumed was similar between treatments. There was a linear decrease in the percentage of feed refused with lower dietary DM concentration. Dietary DM had no effect on milk yield, 4\% FCM yield, or milk component yield (Table 7 ). Milk fat percentage was not affected by dietary DM concentration, but milk protein percentage tended to decrease linearly with the addition of water to the diet. There was a linear increase in the efficiency of production of milk, as well as $4 \%$ FCM, with lower dietary DM concentration (Table 7).

\section{DISCUSSION}

Treatment diets in this study all had the same ingredient and chemical composition but differed in DM concentration because of the addition to the TMR. The addition of water also changed the particle size distribution, increased the amount of DM retained in the medium particle fraction, and reduced the amount of DM retained in the pan. This effect of water addition on feed has been previously seen with feeds of various compositions (Leonardi et al., 2005; Hosseinkhani et al., 2007; Miller-Cushon and DeVries, 2009) and can be attributed to water causing the fine particles to stick to larger particles.

The addition of water to the TMR actually decreased the temperature of the feed at the time of feed delivery because the temperature of the water added was lower than that of the TMR. Despite this, in support of our hypothesis, greater increases in feed temperature in the hours after feed delivery were observed with greater amounts of water added to the ration. Further, also in support of our hypothesis, higher feed temperatures were associated with higher ambient temperature and THI in the barn. Feed temperature was negatively correlated with humidity because feed temperature was lowest at the time of feed delivery at $1000 \mathrm{~h}$, a time when humidity in the barn was typically higher (average: $72.5 \%$ ) than in the afternoon hours (average: $60.9 \%$ at $1300 \mathrm{~h}$ and $56.0 \%$ at $1600 \mathrm{~h}$ ). To our knowledge, there is no previous data on the effects of TMR DM and ambient temperature on feed temperature. Eastridge (2006) suggested that higher moisture TMR are less stable (i.e., more prone to spoilage) during periods of increased environmental temperature. Increased temperature of TMR in the feed bunk over the course of the day has previously been observed and associated with TMR spoilage (Kung et al., 1998). It could be hypothesized that higher moisture in the ration and higher environmental temperature and THI would promote such spoilage in the TMR and thus cause the observed greater temperature increases. It

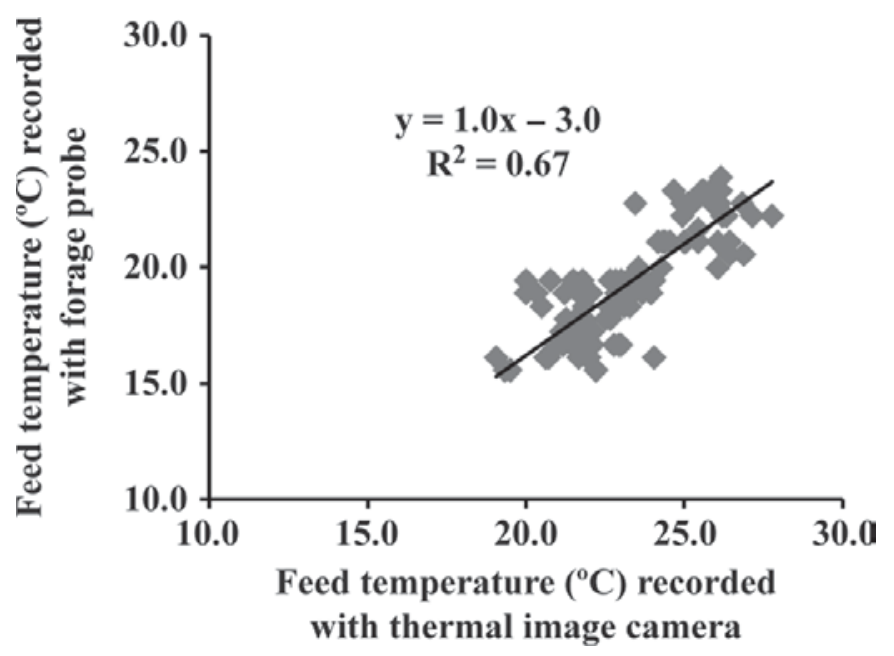

Figure 2. Linear regression model describing the relationship between feed temperature recorded (at 1000, 1300, and $1600 \mathrm{~h}$ ) using a thermal imaging camera and feed temperature recorded using a forage temperature probe. Data are averaged over a single day for 12 cows on each of 3 treatment diets (varying in DM concentration: 56.3, 50.8, and $44.1 \%$ ). 
DIETARY DRY MATTER AND SORTING

Table 5. Effect of dietary treatments on the sorting (\%) of long, medium, short, and fine particles ${ }^{1}$

\begin{tabular}{|c|c|c|c|c|c|c|}
\hline \multirow[b]{2}{*}{ Particle $^{2}$} & \multicolumn{3}{|c|}{ Treatment $^{3}$} & \multirow[b]{2}{*}{$\mathrm{SE}$} & \multicolumn{2}{|c|}{ Effect } \\
\hline & Dry & Wet & Wetter & & Linear & Quadratic \\
\hline$\overline{\text { Long }}$ & $78.1^{* 4}$ & $75.7^{*}$ & $69.4^{*}$ & 3.1 & 0.05 & 0.57 \\
\hline Medium & 99.8 & 99.8 & 99.5 & 0.7 & 0.63 & 0.84 \\
\hline Short & $101.8^{*}$ & $101.4 \dagger$ & $102.8^{*}$ & 0.7 & 0.24 & 0.23 \\
\hline Fine & 97.8 & 99.5 & 95.2 & 4.7 & 0.66 & 0.56 \\
\hline
\end{tabular}

${ }^{1}$ Sorting $\%=100 \times($ particle size $\mathrm{n}$ DMI/particle size $\mathrm{n}$ predicted DMI). Sorting values equal to $100 \%$ indicate no sorting, $<100 \%$ indicate selective refusals (sorting against), and $>100 \%$ indicate preferential consumption (sorting for). Data are averaged over $7 \mathrm{~d}$ for 12 cows on each treatment.

${ }^{2}$ Particle size determined by Penn State Particle Separator, which has a 19-mm screen (long), 8-mm screen (medium), 1.18-mm screen (short), and a pan (fine).

${ }^{3}$ Treatment: dry = basal dry diet without water added; wet = basal dry diet plus $20 \%$ water added (DM basis); wetter $=$ basal dry diet plus $44 \%$ water added (DM basis).

${ }^{4}$ Difference in sorting values from $100 \%$ expressed as $* P<0.05 ; \dagger P<0.10$.

Table 6. Intake of DM, wet matter, feed water, and nutrients, nutrient concentration, and orts percentage of treatment diets ${ }^{1}$

\begin{tabular}{|c|c|c|c|c|c|c|}
\hline \multirow[b]{2}{*}{ Item $^{2}$} & \multicolumn{3}{|c|}{ Treatment $^{3}$} & \multirow[b]{2}{*}{$\mathrm{SE}$} & \multicolumn{2}{|c|}{ Effect } \\
\hline & Dry & Wet & Wetter & & Linear & Quadratic \\
\hline $\mathrm{DMI}, \mathrm{kg} / \mathrm{d}$ & 28.4 & 26.1 & 24.2 & 1.0 & $<0.001$ & 0.59 \\
\hline Wet matter intake, $\mathrm{kg} / \mathrm{d}$ & 48.8 & 49.9 & 54.4 & 2.1 & 0.004 & 0.13 \\
\hline Feed water intake, $\mathrm{kg} / \mathrm{d}$ & 20.4 & 23.8 & 30.2 & 1.2 & $<0.001$ & 0.03 \\
\hline NDF intake, $\mathrm{kg} / \mathrm{d}$ & 9.3 & 8.6 & 8.0 & 0.3 & $<0.001$ & 0.61 \\
\hline $\mathrm{cNDF}, \%$ of $\mathrm{DM}$ & 32.7 & 32.8 & 32.7 & 0.1 & 0.94 & 0.34 \\
\hline Starch intake, $\mathrm{kg} / \mathrm{d}$ & 7.9 & 7.2 & 6.8 & 0.3 & $<0.001$ & 0.35 \\
\hline cStarch, \% of DM & 27.9 & 27.7 & 27.8 & 0.05 & 0.28 & 0.05 \\
\hline Orts, $\%$ & 14.7 & 13.6 & 12.6 & 0.7 & 0.02 & 0.95 \\
\hline
\end{tabular}

${ }^{1}$ Data are averaged over $14 \mathrm{~d}$ for 12 cows on each treatment.

${ }^{2} \mathrm{cNDF}=\mathrm{NDF}$ concentration of diet consumed $=(\mathrm{NDF}$ intake $/ \mathrm{DMI}) \times 100 ; \mathrm{cStarch}=$ starch concentration of diet consumed $=($ starch intake $/ \mathrm{DMI}) \times 100$.

${ }^{3}$ Treatment: dry = basal dry diet without water added; wet $=$ basal dry diet plus $20 \%$ water added (DM basis); wetter $=$ basal dry diet plus $44 \%$ water added (DM basis).

Table 7. Effect of dietary DM concentration on milk yield, milk composition, milk component yield, and efficiency of milk production

\begin{tabular}{|c|c|c|c|c|c|c|}
\hline \multirow[b]{2}{*}{ Item } & \multicolumn{3}{|c|}{ Treatment $^{1}$} & \multirow[b]{2}{*}{$\mathrm{SE}$} & \multicolumn{2}{|c|}{ Effect } \\
\hline & Dry & Wet & Wetter & & Linear & Quadratic \\
\hline \multicolumn{7}{|l|}{ Milk yield, $\mathrm{kg} / \mathrm{d}$} \\
\hline Milk $^{2}$ & 30.5 & 31.3 & 31.1 & 1.6 & 0.66 & 0.80 \\
\hline $4 \% \mathrm{FCM}^{3}$ & 29.5 & 29.5 & 29.4 & 1.4 & 0.96 & 0.97 \\
\hline \multicolumn{7}{|l|}{ Milk composition, ${ }^{3} \%$} \\
\hline Fat & 3.97 & 3.87 & 3.92 & 0.14 & 0.61 & 0.38 \\
\hline Protein & 3.47 & 3.45 & 3.41 & 0.07 & 0.07 & 0.55 \\
\hline \multicolumn{7}{|c|}{ Milk component yield, ${ }^{3} \mathrm{~kg} / \mathrm{d}$} \\
\hline Fat & 1.17 & 1.15 & 1.14 & 0.06 & 0.68 & 0.94 \\
\hline Protein & 1.02 & 1.03 & 1.01 & 0.04 & 0.74 & 0.67 \\
\hline \multicolumn{7}{|c|}{ Efficiency of milk production ${ }^{3}$} \\
\hline Milk/kg of DM & 1.08 & 1.25 & 1.27 & 0.05 & 0.004 & 0.07 \\
\hline $4 \% \mathrm{FCM} / \mathrm{kg}$ of $\mathrm{DM}$ & 1.06 & 1.21 & 1.23 & 0.04 & 0.02 & 0.17 \\
\hline
\end{tabular}

${ }^{1}$ Treatment: dry = basal dry diet without water added; wet = basal dry diet plus $20 \%$ water added (DM basis); wetter $=$ basal dry diet plus $44 \%$ water added (DM basis).

${ }^{2}$ Data are averaged over $7 \mathrm{~d}$ for 12 cows on each treatment.

${ }^{3}$ Data are averaged over $4 \mathrm{~d}$ for 12 cows on each treatment. 
should be noted that feed temperature was recorded only in the $6 \mathrm{~h}$ after feed delivery. Kung et al. (1998) noted 10 to $18^{\circ} \mathrm{C}$ increases in TMR temperature over a 24 -h period. It is very likely that, in the present study, feed temperature would have been much higher at end of the $24 \mathrm{~h}$ the feed was in the bunk than that observed during the 6 -h period. Interestingly, from the thermal imaging of the feed, we noted that there were hot spots in the feed, with temperatures exceeding $30^{\circ} \mathrm{C}$; these hot spots may have been indicative of feed that began to undergo further fermentation and spoilage while in the feed bunk. This use of the thermal image camera to document temperature of feed in the bunk is novel. Given the strong correlation between feed temperature recorded using the thermal image camera and that recorded using a temperature probe, this technology may prove useful in the practical evaluation of changes in feed characteristics in the feed bunk over the course of the day.

Across treatments, cows sorted against the long particles and in favor of the short particles in the TMR. The extent of the sorting in favor of short particles was similar across treatments; however, in support of our hypothesis, greater sorting against long particles was observed with decreased DM concentration of the TMR. Greater sorting behavior with more water in the ration has been previously observed in a ration (contained all ensiled forages and no dry forage) similar to that of the present study (Miller Cushon and DeVries, 2009). The DM concentration of the control rations used in the present study and that by Miller Cushon and DeVries (2009) were much lower $(>20 \%)$ than that tested by Leonardi et al. (2005), who added water to a TMR containing a high proportion of dry forage and found there to be less sorting. It has yet to be demonstrated whether feed sorting can be reduced through water addition to TMR, similar in DM concentration to those tested in the present study, containing dry forages.

Given the sorting against the longer, higher effective fiber particles, and for the shorter, higher starch particles, there could be concern for a risk of SARA (DeVries et al., 2008), particularly for the treatments with added water, and greater long particle sorting. Despite the sorting, the concentration of NDF and starch consumed was similar both across treatments and to that in the original ration provided. This would indicate little biological significance of the sorting observed. For the short particles this is not surprising given that the sorting values were only 1 to $3 \%$ different from that predicted. Even though the long particles were refused at 25 to $30 \%$ of that predicted, this level of sorting would have little effect on overall nutrient consumption given that this particle fraction made up $\leq 3.5 \%$ of the total ration. It could be predicted that such sorting against long particles would have significant effects on nutrient intakes, and associated physiological effects, if the base ration contained a greater proportion of long particles.

Despite similar concentrations of NDF and starch consumed across treatments, the actual intake of these nutrients was reduced, as hypothesized, with greater amounts of water added to the TMR. These results are similar to those of Miller-Cushon and DeVries (2009) and can be attributed to the decrease in DMI observed with water addition to the TMR. The linear decrease in DMI observed with increased water added to the ration provides further evidence that adding too much water to TMR may limit DMI, as also found by Lahr et al. (1983) and Miller-Cushon and DeVries (2009). Similar to that reported by Miller-Cushon and DeVries (2009), it would appear that cows try to compensate for the lower DM concentration of the water-added rations by consuming more total wet feed. Unfortunately, with greater water added to the ration, cows ended up consuming greater amounts of feed water and were not able to achieve the same level of DMI. This lends support to the hypothesis that the water absorbed by the feed may have increased its weight and bulk enough to limit DMI through increased rumen fill (Robinson et al., 1990). Given that the wet matter intake observed in the wetter diet was not as great as that reported by Miller-Cushon and DeVries (2009), the reduction in DMI cannot be completely attributed to increased rumen fill.

There are other possible reasons why DMI declined with greater amounts of water in the TMR. As hypothesized above, the greater increases in feed temperature observed in the higher moisture TMR may have been associated with spoilage of the feed. It is possible that DMI may have been limited if this spoilage was great enough to alter feed palatability (Kung et al., 1998). Another factor that may have contributed to the lower DMI of the water-added rations was the fact that the cows were fed at a lower level, as indicated by the lower orts percentage for these diets. Miller-Cushon and DeVries (2010) recently demonstrated that, even at high levels of overfeeding ( $>10 \%$ orts), DMI may increase with greater amounts of feed provided.

Interestingly, our hypothesis that milk production would be reduced with decreased DMI, and thus decreased nutrient intakes, on the higher moisture TMR was not supported. Despite a similar finding by MillerCushon and DeVries (2009), we made this hypothesis on the expectation that lower nutrient intakes over the longer treatment periods in the present study would be reflected in lower production. The lack of production difference between treatments can be attributed to the fact that the formulated ration could easily support the 
nutrient requirements of the cows, even at the lowest DMI level on the wetter ration. The ration was formulated for cows (at $90 \mathrm{DIM}$ ) producing $40 \mathrm{~kg} / \mathrm{d}$ of milk, with an $\mathrm{NE}_{\mathrm{L}}$ requirement of $42 \mathrm{Mcal} / \mathrm{d}$ (NRC, 2001). Given the actual production level of the cows $(31 \mathrm{~kg} / \mathrm{d})$ and average stage of lactation (156 DIM), their actual $\mathrm{NE}_{\mathrm{L}}$ requirement was only $34 \mathrm{Mcal} / \mathrm{d}$ (NRC, 2001). This level of milk production could have been supported by an even lower DMI level $(21.1 \mathrm{~kg} / \mathrm{d})$ than that observed on the wetter treatment, suggesting that cows consumed above requirements across all treatments. It could be hypothesized that production differences may be observed if these treatments were applied to cows of higher production capacity (e.g., those in early to peak lactation) and thus higher $\mathrm{NE}_{\mathrm{L}}$ requirements.

As a result of the differences in DMI between treatments and lack of production difference, the efficiency of milk production was greater with the TMR lower in DM concentration. It is likely that the overconsumption of energy, particularly on the rations with higher DM percentage tested, would have promoted overconditioning of these animals in the long term. It, therefore, stands to reason that the addition of water to a TMR, formulated for higher production, early-lactation cows, could be used to limit DMI, improve efficiency of production, and reduce the risk of overconditioning in mid- to late-lactation cows. Such a practice would allow for the simplification of feeding programs in that a single TMR could be formulated for both high- and low-production groups, with the low-production group mix having water added in an effort to control DMI level and prevent overconsumption of energy relative to requirements.

Given the lack of milk production difference between treatments, the absence of an effect of milk component yield is not surprising. There was, however, a tendency for milk protein percentage to decrease with increased water content of the ration. Again, the milk protein percentage observed on the wetter ration was similar to that targeted when the diet was balanced. Therefore, it can be hypothesized that the tendency for greater milk protein percentage with less water in the ration may be the result of excess energy intake over that required (Emery, 1978).

Overall, this research provides further support to the findings of Miller-Cushon and DeVries (2009) regarding the effects of water addition on the intake and sorting of a high-moisture TMR containing solely silage and haylage forage sources. Further, this research provides new information on how feed temperature changes while in the feed bunk and how this relates to ambient temperature and ration DM concentration. Further research in this area is still needed to determine exactly why water addition to a TMR, such as that used in this study, may limit DMI. Particularly, research is needed to determine and quantify the relationship between changes in feed temperature and feed spoilage. Further, research is needed to determine whether feed spoilage is a causal factor of the reduced intake and how this spoilage can be controlled. Future studies in this area should also be designed to limit any confounding effects, such as the amount of feed provided, that may affect the level of DMI. Further research is also needed to determine whether the differences in nutrient intakes, as observed, would have a long-term effect on milk production and components in cows with higher production potential than those used in this study. Finally, more research is needed to determine whether water addition to TMR, similar in DM concentration to those tested in the present study, containing dry forages would have the same effect on feed sorting and nutrient intakes.

\section{CONCLUSIONS}

This research provides further evidence that the addition of water to high-moisture TMR containing primarily silage and haylage forage sources reduces nutrient intakes and increases the amount of feed sorting. Greater amounts of water added to such TMR results in greater increases in feed temperature in the hours after feed is placed in the feed bunk, particularly with higher ambient temperatures, and may be indicative of feed spoilage, which may be contributing to the reduced DMI observed. Overall, these results suggest that the addition of water to high-moisture TMR (less than $60 \%$ DM) containing primarily haylage and silage forage sources will not always discourage cows from sorting, but rather may increase this behavior and limit the nutrient consumption of cows. Limiting nutrient consumption through water addition to such TMR may be beneficial in terms of preventing the overconsumption of energy, and thus overconditioning, such as when feeding mid- to late-lactation cows a TMR formulated for high-producing, early-lactation cows.

\section{ACKNOWLEDGMENTS}

We thank the staff and students at the University of Guelph, Kemptville Campus Dairy Education and Research Centre (Kemptville, Ontario, Canada). In particular we thank Megan Bruce, Maarten Kea, Elizabeth Hooper, Angela Greter, and Shannon Beckinsale of the University of Guelph, Kemptville Campus for their technical help. We also thank Alex Venne and Daniel Venne for use of the thermal image camera. We also acknowledge support received from the Natural Sciences and Engineering Research Council of Canada (Ottawa, Ontario, Canada). 


\section{REFERENCES}

AOAC. 2000. Official Methods of Analysis. Vol. I. 17th ed. Association of Official Analytical Chemists International, Arlington, VA.

Bhandari, S. K., S. Li, K. H. Ominski, K. M. Wittenberg, and J. C. Plaizier. 2008. Effects of the chop lengths of alfalfa silage and oat silage on feed intake, milk production, feeding behavior, and rumen fermentation of dairy cows. J. Dairy Sci. 91:1942-1958.

Canadian Council on Animal Care. 1993. Guide to the Care and Use of Experimental Animals. Vol. 1. E. D. Olfert, B. M. Cross, and A. A. McWilliam, ed. CCAC, Ottawa, Ontario, Canada.

DeVries, T. J., K. A. Beauchemin, and M. A. G. von Keyserlingk. 2007. Dietary forage concentration affects the feed sorting behavior of lactating dairy cows. J. Dairy Sci. 90:5572-5579.

DeVries, T. J., F. Dohme, and K. A. Beauchemin. 2008. Repeated ruminal acidosis challenges in lactating dairy cows at high and low risk for developing acidosis: Feed sorting. J. Dairy Sci. 91:3958 3967.

Eastridge, M. L. 2006. Major advances in applied dairy cattle nutrition. J. Dairy Sci. 89:1311-1323.

Emery, R. S. 1978. Feeding for increased milk protein. J. Dairy Sci. $61: 825-828$.

Hosseinkhani, A., R. Valizadeh, A. Naserian, M. D. Mesgharan, and F. E. Shahroodi. 2007. Effect of alfalfa hay particle size and water addition to barley base diets on dairy cows performance in early lactation. J. Anim. Vet. Adv. 6:1482-1488.

Kononoff, P. J., A. J. Heinrichs, and D. R. Buckmaster. 2003. Modification of Penn State forage and total mixed ration particle separator and the effects of moisture content on its measurements. J. Dairy Sci. 86:1858-1863.

Kung, L. Jr., A. C. Sheperd, A. M. Smagala, K. M. Endres, C. A. Bessett, N. K. Ranjit, and J. L. Glancey. 1998. The effect of preservatives based on propionic acid on the fermentation and aerobic stability of corn silage and a total mixed ration. J. Dairy Sci. $81: 1322-1330$
Lahr, D. A., D. E. Otterby, D. G. Johnson, J. G. Linn, and R. G. Lundquist. 1983. Effects of moisture content of complete diets on feed intake and milk production in dairy cows. J. Dairy Sci. 66:1891-1900.

Leonardi, C., and L. E. Armentano. 2003. Effect of quantity, quality, and length of alfalfa hay on selective consumption by dairy cows. J. Dairy Sci. 86:557-564.

Leonardi, C., F. Giannico, and L. E. Armentano. 2005. Effect of water addition on selective consumption (sorting) of dry diets by dairy cattle. J. Dairy Sci. 88:1043-1049.

Miller-Cushon, E. K., and T. J. DeVries. 2009. Effect of dietary dry matter concentration on the sorting behavior of lactating dairy cows fed a total mixed ration. J. Dairy Sci. 92:3292-3298.

Miller-Cushon, E. K., and T. J. DeVries. 2010. Feeding amount affects the sorting behaviour of lactating dairy cows. Can. J. Anim. Sci. 90:1-7.

Morris, T. R. 1999. Experimental Design and Analysis in Animal Sciences. CABI Publishing, New York, NY.

National Research Council. 2001. Nutrient Requirements for Dairy Cattle. Natl. Acad. Sci. Washington, DC.

Ravagnolo, O., I. Misztal, and G. Hoogenboom. 2000. Genetic component of heat stress in dairy cattle, development of heat index function. J. Dairy Sci. 83:2120-2125.

Robinson, P. H., P. L. Burgess, and R. E. McQueen. 1990. Influence of moisture content of mixed rations on feed intake and milk production of dairy cows. J. Dairy Sci. 73:2916-2921.

SAS Institute. 2003. SAS Users Guide. SAS Institute Inc., Cary, NC.

Shaver, R. D. 2002. Rumen acidosis in dairy cattle: Bunk management considerations. Adv. Dairy Tech. 14:241-249.

Van Soest, P. J., J. B. Robertson, and B. A. Lewis. 1991. Methods for dietary fiber, neutral detergent fiber, and nonstarch polysaccharide in relation to animal nutrition. J. Dairy Sci. 74:3583-3597.

Yang, W. Z., and K. A. Beauchemin. 2006. Physically effective fiber: Method of determination and effects on chewing, ruminal acidosis, and digestion by dairy cows. J. Dairy Sci. 89:2618-2633. 